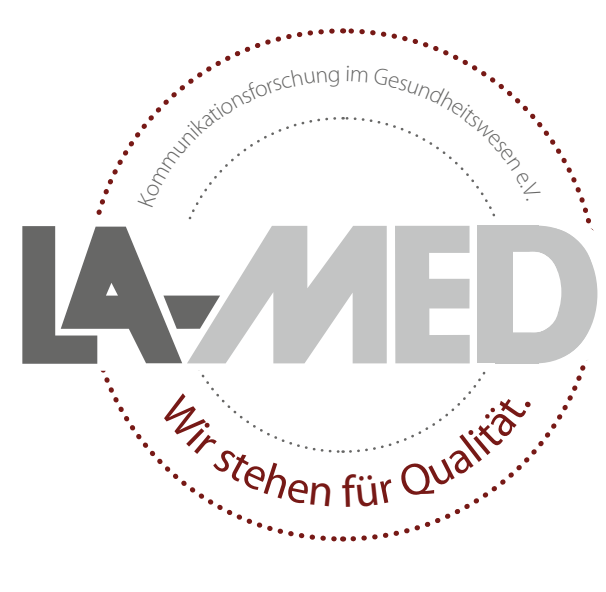

\section{Sie lesen Qualität}

Damit das auch so bleibt, befragen wir Sie in Kooperation mit tns sinfratest in den nächsten Wochen.

\section{Ihr Urteil ist uns wichtig.}

\section{Bitte nehmen Sie teil!}
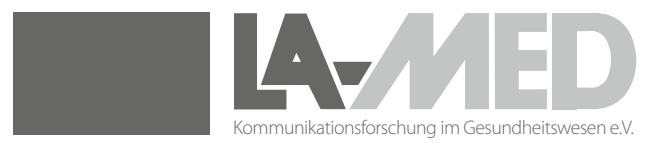

\title{
Auch Typ-1-Diabetiker lassen sich alternativ behandeln
}

Obwohl es bei der Therapie des Typ-1-Diabetes eigentlich keine Alternativen gibt, vertraut ein nicht unwesentlicher Teil der Typ-1-Diabetiker auch Verfahren der Komplementärmedizin.

- Ursache des Typ-1-Diabetes mellitus: Untergang der pankreatischen Betazellen mit nachfolgendem Insulinmangel. Einzig wirksame Therapie: Insulinsubstitution. Es gibt wohl keine Erkrankung, deren Pathophysiologie klarer und deren Therapie logischer ist als der Typ-1-Diabetes mellitus.

Wie eine Umfrage an 342 Probanden mit Typ-1-Diabetes in der Schweiz zeigt, besteht aber auch hier ein Bedürfnis nach der Anwendung von Methoden der Komplementärmedizin. Von den Befragten waren 246 Erwachsene mit einem Altersdurchschnitt von $42 \pm 23$ Jahren und einer mittleren Diabetesdauer von $19 \pm 12$ Jahren. Die pädiatrischen Probanden waren $11 \pm 4$ Jahre alt und hatten eine durchschnittliche Diabetesdauer von $5 \pm 3$,6 Jahren.

Fast 97\% der Erwachsenen und 51\% der Kinder behandelten ihren Diabetes mit einer intensivierten Insulintherapie. 48 Probanden (14\% der Erwachsenen und 18,5\% der Kinder) gaben an, in ihrer Diabetestherapie auch komplementärmedizinische Verfahren benutzt zu haben. Hauptziele waren dabei eine Steigerung des allgemeinen Wohlbefindens, gefolgt von einer Verbesserung der Blutzuckerstabilität, einer Reduktion des Blutzuckerspiegels und der Insulindosis, sowie die Verbesserung der körperlichen Fitness und die Reduktion der Zahl der Hypoglykämien.

Die Empfehlung zur Anwendung von komplementärmedizinischen Methoden erfolgte hauptsächlich durch Freunde und Familienmitglieder (44\%), den Hausarzt (15\%), Komplementärmediziner (15\%) oder die Me-

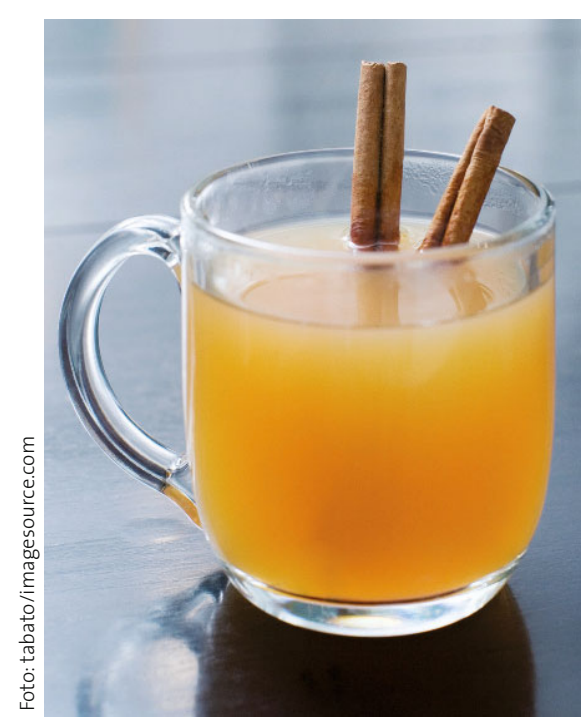

Manche Diabetiker wollen ihren Blutzucker mit Zimt und Tee normalisieren.

dien (6\%). An der Spitze der angewandten Verfahren lag die Supplementation mit Zimt und Magnesium sowie die Anwendung von Diabetikertee. Auch die homöopathische Behandlung, Bioresonanzverfahren und Massagen erfreuen sich einer gewissen Beliebtheit.

KOMMENTAR: Jeder Arzt sollte sich darüber bewusst sein, dass sich seine $P a-$ tienten vielleicht auch ohne sein Wissen komplementärmedizinischen Methoden zuwenden, selbst wenn das Therapieangebot der Schulmedizin logisch und übersichtlich ist. Leider kommt es auch immer wieder vor, dass die Insulintherapie zugunsten eines komplementärmedizinischen Verfahrens verändert oder sogar abgesetzt wird. Man sollte es als Arzt nicht versäumen, nach komplementärmedizinischen Verfahren zu fragen, vor allem wenn der Verlauf des Diabetes eine sonst nicht erklärbare Wendung nimmt.

H. S. FÜEßL =

- U. A. Scheidegger et al.

Rolle der Komplementärmedizin bei Diab etes mellitus Typ-1 in zwei Schweizer Zentren. Praxis 98 (2009) 18, 1001-1005 